\title{
Increasing prevalence of bronchial hyperresponsiveness in three selected areas in East Germany
}

\author{
C. Frye*, J. Heinrich*, M. Wjst*, H-E. Wichmann*,\#, for the Bitterfeld study group
}

Increasing prevalence of bronchial hyperresponsiveness in three selected areas in East Germany. C. Frye, J. Heinrich, M. Wjst, H-E. Wichmann, for the Bitterfeld study group. (C) ERS Journals Ltd 2001.

ABSTRACT: The prevalence of asthma, bronchial hyperresponsiveness (BHR) and allergic rhinitis in children was lower in East Germany compared to West Germany. The reasons for this difference are still not understood. This study tested the hypothesis that prevalence of BHR increased in East German children after reunification.

Two consecutive cross-sectional surveys of schoolchildren aged 8-14 yrs from three communities in East Germany were carried out in 1992-1993 and 1995-1996. A subsample of $\mathbf{5 3 0}$ and $\mathbf{7 9 0}$ children with complete lung function and cold air challenge data was analysed.

The prevalence of BHR increased from $6.4 \%$ in $1992-1993$ to $11.6 \%$ in $1995-1996$ (odds ratio (OR): 2.0, 95\% confidence interval (CI): 1.3-3.0, adjusted for age, sex, season, community and parental education). No changes were found for asthma, allergic rhinitis or allergic sensitization. In contrast, physician diagnosed bronchitis, pneumonia and frequent colds decreased significantly. The observed increase in the prevalence of BHR was reduced (OR: 1.5, 95\% CI: $0.95-2.3$ ) after adjustment for several indoor factors.

In conclusion, while the prevalence of nonallergic respiratory diseases seems to decrease, the prevalence of bronchial hyperresponsiveness might be a first indicator of the suspected increase of asthma prevalence in East Germany. The present results give indirect evidence, that less respiratory infections may be associated with higher bronchial hyperresponsiveness.

Eur Respir J 2001; 18: 451-458.
*GSF - Forschungszentrum für Umwelt und Gesundheit, Institut fur Epidemiologie, Ingolstaedter Landstraße 1, Neuherberg, Germany. ${ }^{\#}$ Lehrstuhl für Epidemiologie, Institut für medizinische Informationsverarbeitung, Biometrie und Epidemiologie der Ludwig-Maximilians-Universität München, Neuherberg, Germany.

Correspondence: J. Heinrich, GSF Forschungszentrum für Umwelt und Gesundheit, Institut fur Epidemiologie, Ingolstaedter Landstraße 1, D-85764 Neuherberg, Germany.

Fax: 498931873380

Keywords: Asthma

atopic diseases

bronchial hyperresponsiveness

children

East Germany

Received: July 252000

Accepted after revision April 232001

This study was supported exclusively by a governmental funding source, the Federal Environmental Agency (Umweltbundesamt) Grant No. 29861 724.
Several studies in Germany carried out after reunification showed a lower prevalence of asthma, bronchial hyperresponsiveness (BHR), hay fever and allergies in children and adults in East Germany compared with West Germany [1, 2]. People born before 1960 had a similar risk for allergic diseases in East and West Germany [3]. Thus, it has been speculated, that changes in living conditions, in environmental and more general in life style (summarized in the rather vague term "western lifestyle") might be responsible for the increasing prevalence of asthma and atopic diseases in western Germany after 1960 [4].

After reunification the political, economical and social life in East Germany changed tremendously. Breakdowns of almost all industries lead to a strong decrease of industrial outputs, accompanied by an increasing unemployment rate. In addition, the Eastern German population rapidly adopted a modern "western lifestyle" [1, 4, 5].

If the slow change of the lifestyle in the West over recent decades was responsible for an increase of allergic diseases in western Germany, the adoption of a western lifestyle in the East within a few years should lead to a steep increase of these diseases in East Germany. Early life seems to be the most critical period for the development of allergic sensitization in later life, as this is the period in which the development of persistent immunoglobulin (Ig)-E reactions to antigens takes place $[6,7]$. Thus changes in the prevalence of allergic diseases are assumed to be detectable in children born around the German reunification in 1990 .

Two repeated cross-sectional studies in East German children showed no consistent findings concerning trends in allergies. A study on fourth grade children (aged 9-11 yrs) from Leipzig, examined in 1991-1992 and 1995-1996 showed a statistically significant increase of allergic sensitization assessed by skin-prick test (OR 1.6, p<0.0001) [8]. This result was not confirmed by a study in Sachsen-Anhalt where no changes in sensitization of children aged 5-7 yrs were found between 1992-1993 and 1995-1996 (assessed by measurement of specific IgE) [5, 9]. Both surveys saw 
no change in the prevalence of asthma. Surveys in 1991-1992 that investigated the self-reported prevalence of asthma in adults found an increase of asthma, wheezing and nocturnal cough in Erfurt (East Germany) but not in Hamburg (West Germany) [10].

There is only one study that investigated trends in BHR after reunification [8]. This study examined children from Leipzig aged 9-11 yrs in 1991-1992 and 1995-1996. Von Mutius et al. [8] saw no increase in the prevalence of BHR.

It was hypothesized that the change in environmental and social life would result in a higher prevalence of asthma, BHR and atopic diseases. BHR is an important component of asthma and can be measured in objective tests.

Therefore, this hypothesis was tested comparing the prevalence of BHR in East German children within two cross-sectional studies in 1992-1993 and 1995-1996.

\section{Material and methods}

\section{Study subjects and study design}

The study was conducted in the state of SachsenAnhalt, Germany (former German Democratic Republic). The main purpose of the study was the regional comparison between the health of children living in the heavily polluted areas of Hettstedt (a region of smelting and copper mining) and Bitterfeld (a centre of chemical production and coal mining) and the control area of Zerbst (a primarily agricultural region) using data on respiratory symptoms and diseases and pulmonary function measurements. The study design and the study areas are described elsewhere in detail $[2,5]$.

The data presented in this paper were collected in two consecutive cross-sectional surveys: the first survey took place between September 1992-July 1993, the second September 1995-July 1996.

The sampling procedure was the same in both surveys. The study population consisted of 5-7-yr-old school entrants, 8-10-yr-old third graders, and 1114-yr-old sixth graders.

The analysis of this report is restricted to the third and sixth graders as pulmonary function tests were only performed in these age groups (table 1). All children of the defined age groups in Zerbst and Hettstedt and those from randomly selected schools in Bitterfeld were invited to participate.

In both surveys children of one class were alphabetically ranked and thereafter alternately tested with spirometry or body plethysmography. In the second survey all children who were selected for the spirometry but had the lung function tested with the body plethysmography in the first survey were additionally sent to the body plethysmography. Therefore, the percentage of children with data from the body plethysmography was higher in the second survey (table 1).

Approval of the study design and the examination protocol was granted by the University of Rostock Ethics Committee. After receiving informed consent,
Table 1.-Number of examinations of children aged 8-14 yrs from three communities in East Germany in 1992-1993 and 1995-1996

\begin{tabular}{lcr}
\hline Population & 1st Survey & 2nd Survey \\
\hline Total response & $1701(89)$ & $2089(75)$ \\
Questionnaire & $1701(100)$ & $2089(100)$ \\
Serum sample & $1152(67.7)$ & $1704(81.5)$ \\
Spirometry or & $1515(89.1)$ & $1778(85.1)$ \\
$\quad$ body plethysmography & $737(100)$ & $1112(100)$ \\
Body plethysmography & $207(28.1)$ & $322(29.0)$ \\
Children without cold air challenge & 200 \\
Not completed cold air challenge & & \\
$\quad$ because of the following reasons: & \\
Current infection ( $</=2$ weeks) & $151(20.5)$ & $189(17.0)$ \\
FEV1 $<80 \%$ & $11(1.5)$ & $16(1.4)$ \\
Raw $>1.11 \mathrm{kPa} \cdot \mathrm{s}^{-1}$ & $19(2.6)$ & $76(6.8)$ \\
No acceptable manoeuvres & $21(2.8)$ & $36(3.2)$ \\
Not reproducible manoeuvres & $12(1.6)$ & $6(0.5)$ \\
Other reasons & $9(1.2)$ & $39(3.5)$ \\
Completed cold air challenge & $530(72)$ & $790(71)$ \\
\hline
\end{tabular}

Data presented $\mathrm{n}(\%)$. The 1 st survey was carried out in 1992-1993 and the 2nd survey was in 1995-1996. Raw: airway resistance; FEV1: forced expiratory volume in one second.

pulmonary function tests and a physical examination were conducted at the schools. Because of the seasonal fluctuations of respiratory health the examination period was spread over one year, changing the location of the examination every two weeks. In the second survey (1995-1996) the same schools were examined in the same period of the year as in 1992-1995.

\section{Questionnaire}

Trained personnel distributed letters explaining the study goals and questionnaires to the children's parents, and completed questionnaires were collected 1 week later. The questionnaire consisted of 78 items and was previously used and tested in several national and international studies and adapted to address East German living and housing conditions. It addressed current and past respiratory diseases, socioeconomic factors, housing conditions, indoor exposure, day care attendance, pet contact, nutritional habits, the parental employment and years of education completed.

\section{Pulmonary function measurements}

Pulmonary function and bronchial responsiveness were assessed in the same way in both surveys by use of a mobile body plethysmograph (Pneumoscop II, Jaeger S.A., Wuerzburg, Germany) and the cold air hyperventilation provocation device mounted on a bus. All tests were performed between 08:00 $\mathrm{h}$ and 14:00 $\mathrm{h}$ and the same technician examined all children in 1992-1993 and 1995-1996.

Subjects performed both forced and slow ventilatory manoeuvres while in a seated position wearing a noseclip. Forced expiratory manoeuvres were repeated until three reproducible tracings were 
obtained that met the standards of the American Thoracic Society (ATS) [11]. The body plethysmograph was calibrated each morning according to the manufacturer's instruction.

Pulmonary function measurements were corrected to body temperature and barometric pressure-saturated. Children were considered to have primary airway obstruction if their prechallenge forced expiratory volume in one second (FEV1) was $<80 \%$ of their forced vital capacity (FVC).

Cold air challenge was performed with a respiratory heat exchange system (Jaeger S.A., Wuerzburg, Germany). The children inhaled dry cold air $\left(-15^{\circ} \mathrm{C}\right.$, measured at the mouthpiece) with $5 \%$ carbon dioxide for $4 \mathrm{~min}$ while hyperventilating at $75 \%$ of their maximal ventilation per minute or 22 times their FEV1 [12]. The ventilatory effort was guided by a balloon, which was filled with cold air at the predetermined rate and had to be kept in a half filled state by the child. Pulmonary function tests were repeated 2-4 min after the cold air challenge.

Children were considered to have BHR to cold air challenge if their postchallenge FEV 1 was $<91 \%$ of their prechallenge FEV1 [13].

\section{Allergic sensitization}

Serum samples were drawn from $>80 \%$ of the children, and were immediately separated by centrifugation, frozen and stored at $-80^{\circ} \mathrm{C}$ until they could be analysed together at the end of the second survey. Specific serum IgE was determined in the Pharmacia laboratory (Freiburg, Germany) with the RAST technique (Pharmacia and Upjohn Diagnostics AB, Uppsala, Sweden). The following antigens were tested: Cladosporium m2, grass g6, Dermatophagoides pteronyssinus $\mathrm{d} 1$, cat $\mathrm{e} 1$, and birch $\mathrm{t} 3$. Levels $\geqslant 0.35$ $\mathrm{IU} \cdot \mathrm{mL}^{-1}$ (level 1 on the radioallergosorbent test (RAST) scale) were considered to be a positive antibody concentration.

\section{Statistical analysis}

Crude prevalence rates and odds ratios with 95\% confidence intervals (CI) were calculated for all binary outcome variables. Multivariate logistic regression analysis was used to assess whether the increase in prevalence of BHR over time could be explained by potential confounding factors. The core model included age, sex, place of residence, and parental education as fixed covariates. Additional confounders were included by a stepwise multiple linear regression. Only variables that were found to have at least a marginally significant relationship (p-value $<0.10)$ were included in the model. As 78 of the third grade children participated in 1992-1993 and 1995-1996, their responses tended to be correlated, which had to be considered in the analyses. The generalized estimating equations (GEE) approach of ZEGER and LIANG [14] was used to account for correlation between repeated observations from the same child. Lung function measurements were analysed as repeated measures.

\section{Results}

The questionnaire was distributed to 1,911 children in 1992-1993 and to 2,785 children in 1995-1996. Parents of 1,701 (89\%) children in the first survey and 2,089 children in 1995-1996 (75\%) returned the questionnaire. Pulmonary function tests were performed on 89\% (1992-1993) and 85\% (1995-1996) of the study population. These children were assigned to a spirometry or body plethysmography with a cold air challenge test. Only those children with acceptable prechallenge spirometry and a prechallenge FEV1 $>80 \%$ of their FVC were eligible for the cold air challenge. Also children with self-reported bronchopulmonary infections within the last 2 weeks or an airway resistance $(R \mathrm{aw})>1.11 \mathrm{kPa} \cdot \mathrm{s}^{-1}$ were excluded from the cold air challenge test. Other exclusion criteria were epilepsy, heart diseases, anxiety in the body plethysmography chamber, technical problems or no adherence to acceptability and reproducibility standards of the ATS [11]. Lung function measurement with completed cold air challenge was assessed in 553 children in 1992-1993 and 790 children in 1995-1996 (table 1). Seventy-eight children (78 of 253 third graders in 1992-1993) performed the cold air-challenge in 1992-1993 and 1995-1996. The response rate for blood sampling was lower in both surveys than the response rate for the lung function testing.

Children with completed cold air challenge were compared between 1992-1993 and 1995-1996 with regard to sex and age and parental education (table 2). Table 2 also shows the changed living conditions in East Germany between 1992-1993 and

Table 2. - Characteristics of children aged 8-14 yrs with completed cold air challenge test from three communities in East Germany in 1992-1993 and 1995-1996

\begin{tabular}{|c|c|c|c|}
\hline & $\begin{array}{l}1 \text { st } \\
\text { Survey }\end{array}$ & $\begin{array}{l}\text { 2nd } \\
\text { Survey }\end{array}$ & p-value* \\
\hline Subject n & 530 & 790 & \\
\hline Sex males & 51.5 & 54.1 & 0.364 \\
\hline Age group $11-14$ yrs & 54.9 & 53.5 & 0.627 \\
\hline Parental education $\%{ }^{\#} \geqslant 12$ yrs & 44.4 & 40.9 & 0.219 \\
\hline Single oven coal & 38.7 & 14.4 & 0.001 \\
\hline Contact to pets & 68.8 & 78.9 & 0.001 \\
\hline Bedroom sharing & 47.5 & 37.8 & 0.001 \\
\hline $\begin{array}{l}\text { Exposure to environmental } \\
\text { tobacco smoke }\end{array}$ & 61.0 & 54.4 & 0.017 \\
\hline Presence of sibling & 81.2 & 80.2 & 0.647 \\
\hline \multicolumn{4}{|l|}{ Age of entry to day nursery } \\
\hline$\leqslant 6$ month & 24.9 & 13.9 & 0.001 \\
\hline $1 \mathrm{yr}$ & 53.7 & 65.5 & 0.001 \\
\hline 2 yrs & 9.3 & 10 & 0.685 \\
\hline Parental history of atopy & 26.3 & 28.8 & 0.283 \\
\hline \multicolumn{4}{|l|}{ Sensitization (IgE, } \\
\hline RAST-FEIA-CAP $\geqslant 1)$ & 33.3 & 31.1 & 0.452 \\
\hline
\end{tabular}

Data presented as \%. The 1 st survey was carried out in 1992-1993, whilst the 2nd survey was in 1995-1996. RASTFEIA-CAP is provided by Pharmacia-Upjohn for determination of serum specific immunoglobulin-E (IgE). *: measured using Chi-squared; \#: measured as highest education of father or mother. 
Table 3.-Prevalence of respiratory diseases, respiratory symptoms and bronchial hyperresponsiveness to cold air challenge in children aged 8-14 yrs with completed cold air challenge test from three communities in East Germany in 1992-1993 and 1995-1996

\begin{tabular}{|c|c|c|c|}
\hline \multirow[t]{2}{*}{ Disorder } & \multicolumn{2}{|c|}{ Prevalence } & \multirow{2}{*}{$\frac{\text { Odds ratio }(95 \% \mathrm{CI})}{2 \text { nd versus } 1 \text { st survey }}$} \\
\hline & 1st Survey & 2nd Survey & \\
\hline \multicolumn{4}{|l|}{ Doctor's diagnosis* } \\
\hline Asthma & $8.0(42 / 523)$ & $6.2(49 / 790)$ & $0.8(0.5-1.2)$ \\
\hline Allergic rhinitis $\#$ & $45(24 / 530)$ & $6.1(48 / 790)$ & $1.4(0.8-2.3)$ \\
\hline Any allergy $\#$ & $15.0(79 / 526)$ & $18.0(141 / 785)$ & $1.2(0.9-1.7)$ \\
\hline Rhinitis (last 12 months) & $67.7(354 / 523)$ & $68.7(543 / 790)$ & $1.0(0.8-1.3)$ \\
\hline$\geqslant 3$ colds (last 12 months) & $35.0(180 / 515)$ & $27.4(210 / 767)$ & $0.7(0.6-0.9)$ \\
\hline Bronchitis & $51.4(269 / 523)$ & $40.5(320 / 790)$ & $0.6(0.5-0.8)$ \\
\hline Pneumonia & $14.2(75 / 530)$ & $10.3(81 / 790)$ & $0.7(0.5-1.0)$ \\
\hline \multicolumn{4}{|l|}{ Symptoms* } \\
\hline Wheezing ${ }^{\#}$ & $21.6(109 / 505)$ & $20.3(159 / 785)$ & $0.9(0.7-1.2)$ \\
\hline Shortness of breath ${ }^{\#}$ & $13.0(65 / 501)$ & $8.4(66 / 782)$ & $0.6(0.4-0.9)$ \\
\hline Cough (last 12 months) & $50.7(265 / 523)$ & $55.2(436 / 790)$ & $1.2(1.0-1.5)$ \\
\hline Cough without cold $\#$ & $5.3(27 / 512)$ & $4.1(32 / 774)$ & $0.8(0.5-1.3)$ \\
\hline Cough in the morning during fall//winter ${ }^{\#}$ & $10.5(52 / 493)$ & $8.0(60 / 753)$ & $0.7(0.5-1.1)$ \\
\hline Allergic sensitization $^{+}$ & $33.3(125 / 375)$ & $31.1(234 / 752)$ & $0.9(0.7-1.2)$ \\
\hline Bronchial hyperresponsiveness ${ }^{\S}$ & $6.4(34 / 530)$ & $11.6(92 / 790)$ & $1.9(1.3-2.9)$ \\
\hline
\end{tabular}

Data is presented as \% (n/total with data). First and second surveys were carried out in 1992-1993 and 1995-1996, respectively. CI: confidence interval. *: as reported by the parents; ${ }^{\#}$ : life time prevalence; ${ }^{\circ}$ : children whose parents reported asthma or asthmatic or spastic bronchitis were defined as having asthma; ${ }^{+}$: at least one specific immunoglobulin-E $\geqslant 0.35$ $\mathrm{kU} \cdot \mathrm{L}^{-1}$ (grass pollen, birch, cat, dermatophagoides pteronyssinus, cladosporium (determined using RAST-FEIA-CAP); $\S$ : decrease of forced expiratory volume in one second $\geqslant 9 \%$ after cold air challenge.

1995-1996. Children of the second survey lived in bigger apartments with a modern heating system, less bedroom sharing and more pets.

Neither physician-diagnosed asthma, allergic rhinitis, nor any kind of allergies changed significantly in the study period. The prevalence of allergic sensitization defined as at least one specific $\operatorname{IgE}$ being Rast class 1 or higher $\left(>0.35 \mathrm{kU} \cdot \mathrm{L}^{-1}\right)$, remained stable. Also, the prevalence of asthma-related symptoms (as reported by the parents) like wheezing, shortness of breath, cough in the last 12 months did not differ in the two surveys (table 3). Physiciandiagnosed bronchitis, pneumonia and frequent colds $(\geqslant 3$ colds in the last year) decreased significantly. Prevalence of BHR increased from 6.4\% in 1992-1993 to $11.6 \%$ in 1995-1996 (Crude OR: $1.9,95 \% \mathrm{CI}$ : 1.3-2.9). Table 4 demonstrates, that early entry to daycare nursery and heating with coal seems to be protective with regard to BHR. Measurements of
FVC and FEV1 did not change significantly between the two surveys (table 5).

The observed increase in the crude BHR remained stable after adjusting for age, sex, season and community and parental education. Taking into account the type of heating and age of entry to day nursery the OR for the prevalence of BHR decreased (table 6). Single oven coal heating (OR: 0.3, CI: $0.1-0.6)$ and early entry to daycare centre (OR: 0.6, CI: $0.3-1.1)$ had strong protective effects with regard to developing BHR.

\section{Discussion}

This study shows that the prevalence of physiciandiagnosed asthma, allergic rhinitis or any allergy did not change in three East Germany communities between 1992-1993 and 1995-1996, but that there

Table 4.-Prevalence of bronchial hyperresponsiveness (BHR) in relation to daycare centre attendance and heating system of children aged 8-14 yrs with completed cold air challenge test from three communities in East Germany in 1992-1993 and 1995-1996

\begin{tabular}{|c|c|c|c|c|}
\hline & \multicolumn{2}{|c|}{ 1st Survey } & \multicolumn{2}{|c|}{ 2nd Survey } \\
\hline & Prevalence & Odds ratio & Prevalence & Odds ratio \\
\hline \multicolumn{5}{|c|}{ Age of entry to day nursery } \\
\hline$\leqslant 6$ month & $3.9(5 / 131)$ & 1 & $7.3(8 / 109)$ & 1 \\
\hline $1 \mathrm{yr}$ & $5.3(15 / 283)$ & $1.4(0.5-4.0)$ & $12.5(64 / 512)$ & $1.8(0.8-3.9)$ \\
\hline $2 \mathrm{yrs}$ & $14.3(7 / 49)$ & $4.2(1.3-14.0)$ & $12.8(10 / 78)$ & $1.9(0.7-5.0)$ \\
\hline \multicolumn{5}{|c|}{ Single oven (coal) } \\
\hline No & $8.5(27 / 317)$ & 1 & $12.7(85 / 668)$ & 1 \\
\hline Yes & $3.0(6 / 200)$ & $0.4(0.1-1.0)$ & $5.4(6 / 112)$ & $0.5(0.2-1.2)$ \\
\hline
\end{tabular}

Data presented as $\%(\mathrm{n} /$ total with data) and odds ratio $(95 \%$ confidence interval $(\mathrm{CI}))$. 
Table 5. - Pulmonary function of children aged 8-14 yrs with completed cold air challenge test from three communities in East Germany in 1992-1993 and 19951996

\begin{tabular}{|c|c|c|c|}
\hline & 1st Survey & 2nd Survey & p-value* \\
\hline Subject $n$ & 530 & 790 & \\
\hline \multicolumn{4}{|c|}{ Before cold air challenge test } \\
\hline FEV1 L & $2.32 \pm 0.49$ & $2.29 \pm 0.53$ & 0.30 \\
\hline FVC L & $2.58 \pm 0.58$ & $2.55 \pm 0.60$ & 0.31 \\
\hline \multicolumn{4}{|c|}{ After cold air challenge test } \\
\hline FEV1 L & $2.28 \pm 0.49$ & $2.22 \pm 0.53$ & 0.05 \\
\hline FVC L & $2.57 \pm 0.58$ & $2.53 \pm 0.60$ & 0.16 \\
\hline
\end{tabular}

Data presented as mean \pm SE. 1st survey was conducted 1992-1993 whilst the second was 1995-1996. FEV1: forced expiratory volume in one second; FVC: forced vital capacity. *: p-value calculated with the proc mixed method to account for correlation between repeated observations from the same child.

was a significant increase of BHR between both surveys. The observed crude increase in the prevalence of BHR from 1992-1993 to 1995-1996 can be partially explained by the reduction of protective indoor factors. Adjusting for the type of heating, age of entry to day nursery and bedroom sharing reduced the OR from 1.9-1.5.

To the best of the authors' knowledge, the present analysis is the first that reports an increase of BHR in East Germany. Von Mutius et al. [8] found no change in BHR among fourth graders between 1991-1992 and 1995-1996 in Leipzig. The prevalence or BHR was $6.5 \%$ in $1991-1992$ and $6.3 \%$ in 1995-1996. Leipzig is an industrial town with $\sim 500,000$ inhabitants (region of Bitterfeld: 110,000 inhabitants). Younger children might be more susceptible to changes causing BHR. The children investigated in Leipzig were of a different age (fourth grade) than the children examined in the present study (third and sixth grade). Although the increase in BHR in the present data was detectable

Table 6. - Results of multivariate logistic regression anaIysis (generalized estimating equations (GEE)-method) with bronchial hyperresponsiveness (BHR) as outcome variable in children aged 8-14 yrs with completed cold air challenge test from three communities in East Germany in 1992-1993 and 1995-1996

\begin{tabular}{|c|c|c|}
\hline & BHR & p-value \\
\hline $\begin{array}{l}\text { 2nd Survey versus } 1 \text { st Survey, } \\
\text { crude }\end{array}$ & $1.9(1.3-2.9)$ & 0.002 \\
\hline 2nd Survey versus 1st Survey & $2.0(1.3-3.0)$ & 0.002 \\
\hline 2nd Survey versus 1st Survey* & $1.5(1.0-2.3)$ & 0.084 \\
\hline $\begin{array}{l}\text { Age of entry to day nursery } \\
\leqslant 6 \text { month } \\
\text { Single oven (coal) }\end{array}$ & $\begin{array}{l}0.6(0.3-1.1) \\
0.4(0.2-0.7)\end{array}$ & $\begin{array}{l}0.12 \\
0.0007\end{array}$ \\
\hline
\end{tabular}

Data presented as odds ratio ( $95 \%$ confidence interval). BHR was defined as a decrease in forced expiratory volume of $\geqslant 9 \%$ from baseline after cold air challenge. All were adjusted for age, sex, season, community and parent's education in addition to. *: age of entry to day nursery $\leqslant 6$ month and single oven (coal); ${ }^{\#}$ : survey and single oven (coal); ${ }^{\uparrow}$ : survey and age of entry to day nursery $\leqslant 6$ month; ${ }^{+}$: yes versus no. for third graders $(p=0.007)$ and sixth graders $(p=0.08)$, the observed increase was less pronounced in the older children and not statistically significant.

Von Mutius et al. [8] described an increase in the prevalence of hay fever and atopic sensitization (skinprick test) in children aged 9-11 yrs between 1991-1992 and 1995-1996 in Leipzig, in that study there was no change in the prevalence of asthma, asthma-related symptoms, or BHR. In contrast, a survey in Sachsen-Anhalt found an increase in selfreported physician-diagnosed allergies in children aged 5-7 yrs, but not in allergic sensitization (RAST-CAP-FEIA method), asthma, allergic rhinitis or self reported symptoms of allergic diseases [5]. KRAEMER et al. [15] investigated time trends in four East German cities and found no differences for allergies and related symptoms.

Although studies on the prevalence in the past were consistent concerning the East-West differences, studies investigating the change in the prevalence of atopic diseases in Eastern Germany after reunification are inconsistent within surveys and between surveys. So far there is no convincing evidence for an increase in the prevalence of atopic diseases in East Germany. Since early life seems to be the critical period for the development of allergic sensitization in later life, it might be argued, that children and adults examined in those surveys were not exposed to "western" risk factors in the early critical time period (table 7).

Significant risk factors for BHR in the analysis were allergic sensitization, diagnosed asthma, and younger age. This is consistent with the literature [16-18]. These factors did not change in the two surveys and can, therefore, not be responsible for the changing prevalence of BHR. It was hypothesized, however, that the changing lifestyle in East Germany leads to an increase of BHR and two factors that changed within the two surveys and had an effect on BHR were found: single coal oven and early age of entry to day nursery. Both of them are known to be associated with a higher risk of infections [19-21]. Previous reports have pointed towards a protective role of early childhood exposure to infections diseases for the development of atopic diseases [7, 22]. This hypothesis is strengthened by the fact, that there are less atopic diseases in daycare centres [21], with siblings [23] or with coal or wood heating [24, 25].

KRAEMER et al. [21] found that in children from small families (up to three people), the prevalence of atopy was higher among children who started to attend day nursery at an older age than those who started at to attend at a younger age. The model suggested by KrAEMER et al. [21] was used on the presented data. Compared with children who first attended the daycare nursery at age 6 months, the adjusted OR for BHR were 1.7 (95\% CI: 0.9-3.2) for children who attended at age 12 month and $1.6(95 \%$ CI: $1.1-2.2)$ for those who attended at age 24 months and older. These findings support the hypothesis that early infections may protect against BHR in later life.

However, the lower percentage of children who went to a daycare centre at a very early age in 1995-1996 (table 2) is not due to the changing lifestyle because of the fall of the Berlin wall but is 
Table 7. - Comparison of trends of allergic and respiratory diseases in Eastern Germany

\begin{tabular}{|c|c|c|c|c|c|c|c|c|}
\hline & $\begin{array}{c}\text { Present } \\
\text { study } \\
1995-1996 \\
\text { versus } \\
1992-1993\end{array}$ & $\begin{array}{c}\text { Sachsen } \\
\text { Anhalt [5] } \\
1995-1996 \\
\text { versus } \\
1992-1993\end{array}$ & $\begin{array}{c}\text { Leipzig } \\
\text { [8] } \\
1995-1996 \\
\text { versus } \\
1991-1992\end{array}$ & $\begin{array}{c}\text { Leipzig } \\
{[15]} \\
1995 \\
\text { versus } \\
1992\end{array}$ & $\begin{array}{c}\text { Halle } \\
{[15]} \\
1995 \\
\text { versus } \\
1992\end{array}$ & $\begin{array}{c}\text { Magdeburg } \\
{[15]} \\
1995 \\
\text { versus } \\
1992\end{array}$ & $\begin{array}{c}\text { Altmark } \\
{[15]} \\
1995 \\
\text { versus } \\
1992\end{array}$ & $\begin{array}{c}\text { Erfurt } \\
{[5]} \\
1994-1995 \\
\text { versus } \\
1990-1992\end{array}$ \\
\hline Age yrs & $8-14$ & $5-7$ & 9-11 & $5-8$ & $5-8$ & $5-8$ & $5-8$ & $19-45$ \\
\hline $\begin{array}{l}\text { Males/females } \mathrm{n} \\
\text { Allergic diseases/symptoms }\end{array}$ & $530 / 790$ & $769 / 725$ & $1854 / 2666$ & $571 / 412$ & $1240 / 399$ & $1333 / 296$ & $929 / 762$ & $3273 / 2876$ \\
\hline Allergy ever* & $=$ & $\uparrow$ & ne & $\downarrow$ & $=$ & $=$ & $\downarrow$ & ne \\
\hline Asthma ever* & $=$ & $=$ & $=$ & $=$ & $=$ & $=$ & $=$ & $\uparrow$ \\
\hline Hay fever ever* & $=$ & $=$ & $\uparrow$ & $=$ & $=$ & $=$ & $=$ & ne \\
\hline Wheeze ever* & $=$ & ne & $\downarrow$ & $=$ & $=$ & $\downarrow$ & $=$ & $\uparrow$ \\
\hline Sensitization (skin-prick test) & ne & ne & $\uparrow$ & ne & ne & ne & ne & ne \\
\hline Sensitization (RAST) & $=$ & $=$ & ne & ne & ne & ne & ne & ne \\
\hline BHR & $\uparrow$ & ne & $=$ & ne & ne & ne & ne & ne \\
\hline Non allergic respiratory diseases & & & & & & & & \\
\hline Bronchitis ever* & $\downarrow$ & $\downarrow$ & $\downarrow$ & $=$ & $\downarrow$ & $\downarrow$ & $\downarrow$ & ne \\
\hline$\geqslant 3$ colds in one last 12 month* & $\downarrow$ & ne & ne & $\downarrow$ & $\downarrow$ & $=$ & $=$ & ne \\
\hline
\end{tabular}

BHR: bronchial hyperresponsiveness defined as a decrease in forced expiratory volume in one second $\geqslant 9 \%$ from baseline after cold air challenge; *: questionnaire; ne: not examined-no data available; $\downarrow$ : significant decrease of prevalence; $\uparrow:$ significant increase of prevalence; =: no change.

probably caused by a change in law in 1986. From that time on, mothers with a firstborn could get $1 \mathrm{yr}$ of paid maternity. Before 1986, mothers of a firstborn child were entitled to only 6 months of paid leave.

While heating with coal or wood appears to be protective, in respect to atopic diseases, electric heating [20] or gas cooking [25] seems to have a harmful effect. However, the heating system might only be an indicator for a more traditional way of living (wood of coal) or more "western" lifestyle (central/electric heating).

In the present analysis of children living with a single coal oven, the parental educational level was lower, the children were significantly more exposed to tobacco smoke, they were more often in daycare centres at a younger age, shared their bedroom, lived in smaller homes and had more mould and humidity in their homes. If the "western lifestyle" is responsible for the rise of BHR, coal heating might be a surrogate for a more traditional lifestyle without or with slower adoption of western lifestyle.

The heating system is a parameter that changed after reunification. The youngest children from the second survey were 2 yrs old in 1990. This suggests, that the development of BHR is not solely restricted to the first 2 yrs of life.

After reunification pollution with sulphur dioxide $\left(\mathrm{SO}_{2}\right)$ and total suspended particles (TSP) decreased noticeably [5, 15]. The decline of air pollution is accompanied with a decrease in nonallergic inflammatory airway diseases like bronchitis or pneumonia. So far there is no data on the ultra-fine particles. Accompanied by a major increase of traffic, ultra-fine particles might have increased and thus, be a possible explanation for the increase in BHR. This remains to be investigated.

Viral infections of the airways can lead to BHR [26]. Although children with respiratory infections within the last 2 weeks were excluded, one might argue that more serious infections could lead to a BHR for more than 2 weeks. If there would have been an epidemic of respiratory infections in the second survey this could lead to a higher BHR rate. And indeed there was an influenza epidemic in December 1995 and January 1996 (H. Opperman, Hygieneinstitut Sachsen - Anhalt, Walloner Berg 2-3, Magdeburg, Germany, personal communication). Nevertheless, the higher BHR prevalence was constantly twice as high in the second survey throughout the whole year. Therefore, the influenza epidemic in 1995 and 1996 does not seem to contribute to the higher prevalence of BHR in 1995-1996. BHR is an important component of asthma [16, 27, 29]. BHR differentiates the group of asthmatic children with the most severe, ongoing impairment [16]. Most importantly, BHR is a strong risk factor for asthma [30]. In a 2-yr follow-up study among 81 students (11-17 yrs) who were found to have BHR in a population survey $(n=3,067), \sim 45 \%$ of asymptomatic students developed asthma in the following 2 yrs [27]. An Austrian study showed that asthma is often underdiagnosed. A clinical investigation of all children that had BHR or an abnormal lung function (defined as an FEV $1<80 \%$ of the predicted value) in an epidemiological study revealed that about half of the children had unknown asthma [31]. Thus, the rise in prevalence of the present study could be the first sign of an increasing prevalence of asthma in East Germany. This result is strengthened by the fact that the baseline airway resistance $\left(R a w>1.1 \mathrm{kPa} \cdot \mathrm{s}^{-1}\right)$ in the present population increased significantly between the first and the second survey (OR: 3.0, CI: 1.6-5.3). Furthermore, the prevalence of the children with increased baseline airways resistance $($ Raw $>1.11)$ or baseline airways obstruction (FEV1 <80\%) or enhanced BHR changed significantly in 1995-1996 (OR: 2.1; CI: 1.5-2.8).

A major strength of this study is the use of identical methods in both surveys. The same equipment was used in both surveys. One technician performed all the lung function tests of both surveys. The approach to 
the children and the flow of the examination were identical. The cold air challenge is a before and after test. Therefore, test results are less biased by changed methods, equipment or encouragement of the nurse. Better helping of the nurse would not result in a higher BHR prevalence since this better helping would lead to better expiratory flows before and after the provocation, thus having the same BHR rates as another examiner. Therefore, it is unlikely that technical differences in performing the BHR measurements between the two surveys can explain the results.

In an epidemiological study like this, several aspects of possible bias and confounding have to be addressed. First of all, there are only two measurements from two cross-sectional surveys. In addition, children came from three regions in East Germany. There is no control group from West Germany to estimate possible secular trends. There was no metropolitan area involved. So, the results might be restricted to the local population or to more rural areas. If the major time for expecting an influence of the changing environment after reunification on asthma outcome is the early childhood, the present study might have been conducted too early. Unfortunately it was not possible to perform cold air challenge again in a third survey that was undertaken in 1998-1999.

Shortly after the breakdown of the communistic regime it was very easy to motivate people to take part in a study that was carried out with the close collaboration of the local health department. This changed in later years and made it much more difficult to motivate children and their parents to participate. However, the participation rate was high in both surveys, 89\% (1992-1993) and 75\% (1995-1996) of the children took part in the study. Nonetheless, selection bias may partially be responsible for the change in BHR. Another possible bias could be that children who had BHR in 1992-1993 were more likely to participate in the second survey than children without BHR. The comparison of participants of the first survey who were re-examined in 1995-1996 and those who were only examined in 1992-1993 showed no significant difference in the BHR prevalence. Consequently, response bias is unlikely.

The population studied increased in size between the first and the second survey (table 1). The reason for this is, that between the first and the second survey major changes took place in East Germany. Schools were closed and pooled together resulting in more pupils in the schools analysed. There was no geographic movement that might have influenced the results.

In conclusion, whether the change of bronchial hyperresponsiveness prevalence is caused by indoor or outdoor sources, the data seem to support the hypothesis of a protective element of early respiratory infections. Changes in lifestyle or environment after the first year of life seem to have an effect on the bronchial hyperresponsiveness of children in later life. This might be the first hint of an increasing prevalence of asthma and atopic diseases due to changes towards a "western lifestyle" in Eastern Germany.
Acknowledgements. The authors wish to thank H. Schneller and K. Honig-Blum for data handling, H. Adam and $H$. Bach for examining the children, I. Hörhold, I. Keller, S. Löwe and D. Bodesheim for collecting the blood and urine specimens, T. Schäfer and J. Ring for advise concerning the dermatological examinations, G. Burmester, J. Rudzinski, B. Hollstein, H. Machander, D. Albrecht and C. Böttcher for gathering regional data and local assistance, all teachers in Hettstedt, Zerbst and Bitterfeld and the local school authorities and healthcare centres for their support, all parents and children for their participation.

\section{References}

1. Von Mutius E, Martinez FD, Fritzsch C, Nicolai T, Roell G, Thiemann HH. Prevalence of asthma and atopy in two areas of West and East Germany. Am J Respir Crit Care Med 1994; 149: 358-364.

2. Heinrich J, Hoelscher B, Wjst M, Ritz B, Cyrys J, Wichmann HE. Respiratory diseases and allergies in two polluted areas in east Germany. Env Health Perspect 1999; 107: 53-62.

3. Heinrich J, Nowak D, Wassmer G, et al. Agedependant differences in the prevalence of allergic rhinitis and atopic sensitization between an eastern and a western German city. Allergy 1998; 53: 89-93.

4. Wichmann HE. Possible explanation for the different trends of asthma and allergy in East and West Germany. Clin Exp Allergy 1996; 256: 621-623.

5. Heinrich J, Hoelscher B, Jacob B, Wjst M, Wichmann HE. Trends in Allergies among Children in a Region of Former East Germany between 1992-1993 and 1995-1996. Eur J Med Res 1999; 4: 107-113.

6. Martinez FD, Wright AL, Taussig LM, Holberg CJ, Halonen M, Morgan WJ. Asthma and wheezing in the first six years of life. The Group Health Medical Associates. N Engl J Med 1995; 332: 133-138.

7. Holt PG. Infections and the development of allergy. Toxicol Lett 1996; 86: 205-210.

8. Von Mutius E, Weiland SK, Fritzsch C, Duhme H, Keil U. Increasing prevalence of hay fever and atopy among children in Leipzig, East Germany. Lancet 1998; 351: 862-866.

9. Heinrich $\mathbf{J}$, Wjst $M$. Increase of allergy in East Germany. Lancet 1998; 351: 1813.

10. Heinrich J, Richter K, Magnussen H, Wichmann HE. Is the prevalence of atopic diseases in East and West Germany already converging? Eur J Epidemiol 1998; 14: 239-245.

11. American TS. Standardisation of Spirometry. Am Rev Respir Dis 1987; 136: 1285-1298.

12. Zach M, Polgar G, Kump H, Kroisel P. Cold air challenge of airway hyperreactivity in children: Practical application and theoretical aspects. Pediatr Res 1984; 18: 469-478.

13. Wjst M, Dold S, Reitmeir P, Wulff A, Nicolai T, Von Mutius E. Evaluation of cold air challenge data in a population sample using a model of bronchial hyperreactivity and disposition to bronchial obstruction. Pediatr Pulmonol 1993; 15: 339-344.

14. Zeger SL, Liang KY. Longitudinal data analysis for discrete and continuous outcomes. Biometrics 1986; 42: 121-130. 
15. Kramer U, Behrend H, Dolgner R, et al. Airway diseases and allergies in East and West German children during the first five years after the reunification: time trends and the impact of sulfur dioxide and total suspended particles. Int J Epidemiol 1999; 28: 865-873.

16. Peat JK, Toelle BG, Salome CM, Woolcock AJ. Predictive nature of bronchial responsiveness and respiratory symptoms in a one year cohort study of Sydney schoolchildren. Eur Respir J 1993; 6: 662-669.

17. Nicolai E, Von Mutius E, Reitmeir P, Wjst M. Reactivity to cold-air hyperventilation in normal and in asthmatic children in a survey of 5697 schoolchildren in Southern Bavaria. Am Rev Respir Dis 1993; 147: 565-572.

18. Backer V, Groth S, Dirksen A, et al. Sensitivity and specificity of the histamine challenge test for the diagnosis of asthma in an unselected sample of children and adolescents. Eur Respir J 1991; 4: 1093 1100 .

19. Celedon JC, Litonjua AA, Weiss ST, Gold DR. Day care attendance in the first year of life and illnesses of the upper and lower respiratory tract in children with a familial history of atopy. Pediatrics 1999; 104: 495500.

20. Infante-Rivard C. Childhood asthma and indoor environmental risk factors. Am J Epidemiol 1993; 137: 834-844.

21. Kramer U, Heinrich J, Wjst M, Wichmann HE. Age of entry to day nursery and allergy in later childhood. Lancet 1999; 353: 450-454.

22. Martinez FD. Role of viral infections in the inception of asthma and allergies during childhood: could they be protective. Thorax 1994; 49: 1189-1191.

23. Bodner C, Godden D, Seaton A. Family size, childhood infections and atopic diseases. The Aberdeen WHEASE Group. Thorax 1998; 53: 28-32.
24. Von Mutius E, Illi S, Nicolai T, Martinez FD. Relation of indoor heating with asthma, allergic sensitisation, and bronchial responsiveness: survey of children in south Bavaria. BMJ 1996; 312: 14481450.

25. Volkmer RE, Ruffin RE, Wigg NR, Davies N. The prevalence of respiratory symptoms in South Australian preschool children. II. Factors associated with indoor air quality. J Paediatr Child Health 1995; 31: $116-120$

26. Riedel F, Oberdieck B, Streckert HJ, Philippou S, Krusat T, Marek W. Persistence of airway hyperresponsiveness and viral antigen following respiratory syncytial virus bronchiolitis in young guinea-pigs. Eur Respir J 1997; 10: 639-645.

27. Zhong NS, Chen RC, Yang MO, Wu ZY, Zheng JP, $\mathrm{Li} \mathrm{YF}$. Is asymptomatic bronchial hyperresponsiveness an indication of potential asthma? A two-year follow-up of young students with bronchial hyperresponsiveness. Chest 1992; 102: 1104-1109.

28. Hopp RJ, Townley RG, Biven RE, Bewtra AK, Nair NM. The presence of airway reactivity before the development of asthma. Am Rev Respir Dis 1990; 141: 2-8.

29. Pattemore PK, Asher MI, Harrison AC, Mitchell EA, Rea HH, Stewart AW. The interrelationship among bronchial hyperresponsiveness, the diagnosis of asthma, and asthma symptoms. Am Rev Respir Dis 1990; 142: 549-554.

30. Ulrik CS, Backer V, Hesse B, Dirksen A. Risk factors for development of asthma in children and adolescents: findings from a longitudinal population study. Respir Med 1996; 90: 623-630.

31. Eder W, Gamper A, Oberfeld G, Riedler J. Clinical follow-up of an epidemiologic study on asthma and allergies in childhood. Wien Klin Wochenschr 1998; 110: 678-685. 